\title{
Correlated selection responses for female fertility after selection for high protein yield or low mastitis frequency in Norwegian Red cows
}

\author{
B. Heringstad ${ }^{*} \dagger^{1}$ and $A$. G. Larsgard $\dagger$ \\ *Department of Animal and Aquacultural Sciences, Norwegian University of Life Sciences, N-1432 Ås, Norway \\ †Geno Breeding and Al Association, N-1432 Ås, Norway
}

\begin{abstract}
Correlated selection responses in female fertility were estimated from a selection experiment with 2 groups of Norwegian Red cows selected for high protein yield (HPY) and low mastitis frequency (LCM), respectively. Genetic trends were calculated for nonreturn rate within $56 \mathrm{~d}$ after first insemination (NR56) for heifers, first-lactation cows, and second- and third-lactation cows, calving interval between first and second calving (CIN), and interval from calving to first insemination (CFI) for first-lactation cows and for second- and thirdlactation cows. A total of 5,001 cows from the selection experiment had estimated breeding values for fertility, of which 2,806 were HPY and 2,195 were LCM cows. Permutation tests showed significant genetic differences between LCM and HPY for all fertility traits except CFI for second- and third-lactation cows. Observed differences between mean EBV in HPY and in LCM were, with few exceptions, far outside the range of the permutation test (i.e., significantly different from zero). LCM cows were, in general, genetically more fertile than HPY cows, with higher NR56 in heifers and cows, shorter CIN, and shorter CFI in first lactation. Genetic differences between HPY and LCM after 6 cow-generations were 2.5 percentage units NR56 in heifers, 2 percentage units NR56 in cows, and $4 \mathrm{~d}$ for CIN. No difference was found for CFI in second and third lactation. This is the first report of genetic change in female fertility as a correlated response after selection against mastitis.
\end{abstract}

Key words: correlated selection response, dairy cow, female fertility, mastitis

\section{INTRODUCTION}

Estimates of antagonistic genetic relationships between milk production and female fertility in dairy cattle vary from close to 0 to 0.5 (e.g., Roxström et al.,

Received May 4, 2010.

Accepted August 26, 2010.

${ }^{1}$ Corresponding author: bjorg.heringstad@umb.no
2001; Andersen-Ranberg et al., 2005). Favorable genetic correlations have been found between clinical mastitis (CM) and various fertility traits, ranging from close to 0 to 0.41 (Kadarmideen et al., 2000; Andersen-Ranberg and Heringstad, 2006; Heringstad et al., 2006a). Correlated selection responses in female fertility, in opposite directions, can therefore be expected after selection for increased milk production and selection against mastitis, respectively.

A Norwegian selection experiment with 2 groups of cows selected for high protein yield (HPY) and low CM frequency (LCM) provided the data necessary to calculate correlated responses in female fertility. Large genetic differences in mastitis resistance have been reported from this selection experiment. After 5 cowgenerations, the genetic differences between the 2 selection groups approached 10 percentage units $\mathrm{CM}$ and 25 kg 305-d protein yield (Heringstad et al., 2007).

The objective of this study was to estimate correlated responses in female fertility after selection for increased protein yield in HPY and selection against mastitis in LCM.

\section{MATERIALS AND METHODS}

\section{Selection Experiment}

The selection experiment started in 1989 and includes 9 herds, each with approximately the same number of cows in the 2 selection groups HPY and LCM (Heringstad et al., 2007). The best proven sires for a given trait (protein yield or mastitis) were each year selected among the 120 to 130 progeny-tested Norwegian Red bulls and used as sires in the experiment. Cows in HPY were mated to the 3 to 4 highest-ranking proven sires for protein yield and LCM cows were mated to the 2 to 4 best proven sires for mastitis resistance. Thus, the experiment is based on single trait selection of sires preselected for the Norwegian Red breeding objective.

For these analyses, all cows present in the herds when the selection experiment started that had been mated with one of the defined sires and produced a daughter that had a first lactation record, were defined as 
Table 1. Summary statistics for the high-protein-yield (HPY) and low-clinical-mastitis (LCM) group cows in cow-generations (gen) 0 and 4 to 6, together with mean values from the Norwegian Red population (1978-2009)

\begin{tabular}{|c|c|c|c|c|c|}
\hline \multirow[b]{2}{*}{ Fertility trait ${ }^{1}$} & \multicolumn{2}{|c|}{ LCM } & \multicolumn{2}{|c|}{ HPY } & \multirow{2}{*}{$\begin{array}{c}\text { Norwegian } \\
\text { Red } \\
(1978-2009)\end{array}$} \\
\hline & gen 0 & gen $4-6$ & gen 0 & gen $4-6$ & \\
\hline NR56, first lactation, mean & 0.62 & 0.78 & 0.67 & 0.66 & 0.68 \\
\hline NR56, second and third lactation, mean & 0.65 & 0.73 & 0.65 & 0.70 & 0.69 \\
\hline CIN, mean d & 377 & 364 & 377 & 375 & 381 \\
\hline CFI first lactation, mean $\mathrm{d}$ & 71 & 72 & 75 & 74 & 81 \\
\hline
\end{tabular}

${ }^{1} \mathrm{NR} 56=$ nonreturn within $56 \mathrm{~d}$ after first insemination, $\mathrm{CIN}=$ interval between first and second calving, CFI $=$ interval from calving to first insemination.

belonging to cow-generation 0 . Their daughters were defined as cow-generation 1 and so on. Cows born in the same year may therefore belong to different cowgenerations.

\section{Breeding for Fertility in Norwegian Red}

Cow fertility is an important trait in the breeding objective for Norwegian Red cows and has been included in the total merit index used for selection of Norwegian Red sires since 1972 (Geno Global, 2010). Since 1972 , the fertility trait used in genetic evaluation has been nonreturn rate within $56 \mathrm{~d}$ after first insemination (NR56) in heifers. In 2001, NR56 for cows was included in a fertility index, and since 2008, the fertility index has also included interval from calving to first insemination (CFI) (Larsgard, 2008). The 3 trait groups receiving the highest relative weight in the total merit index are milk production (28\%), mastitis (21\%), and fertility (18\%) (Geno Global, 2010). Over the last $20 \mathrm{yr}$, the relative weights have been from 19 to $28 \%$ for milk production, between 19 and $25 \%$ for mastitis, and from 12 to $18 \%$ for fertility. Norwegian Red sires are progeny tested based on large daughter groups (on average, more than 250 daughters with fertility data) and it is therefore also possible to obtain reliable EBV and genetic improvement for traits with low heritability, such as cow fertility.

\section{Data and Breeding Values}

Data were from the Norwegian Dairy Herd Recording System and fertility EBV for cows were from the September 2009 routine national genetic evaluation of Norwegian Red cows. Traits included were NR56 for heifers, NR56 for first-lactation cows, NR56 for secondand third-lactation cows, calving interval between first and second calving (CIN), CFI for first-lactation cows, and CFI for second- and third-lactation cows. In the national genetic evaluation of Norwegian Reds, all data on these 6 traits from 1978 onward (including the selection experiment herds) are analyzed using multivariate animal models. Models and parameters are described by Larsgard (2008) and Interbull (2010).

The trait NR56 was scored as 1 or 0 based on whether the cow had a second insemination (other than double inseminations; i.e., a new insemination $0-5 \mathrm{~d}$ after the first) within $56 \mathrm{~d}$ after the first insemination. Mean NR56 for the 2.7 million cows included in the routine genetic evaluation was 0.75 for heifers, 0.68 for firstlactation cows, and 0.69 for second- and third-lactation cows. The CFI had to be between 20 and $210 \mathrm{~d}$, and had a mean of $81 \mathrm{~d}$ for first-lactation cows and $80 \mathrm{~d}$ for second- and third-lactation cows. The mean number of days between first and second calving (CIN) was 381 . Summary statistics for cows in the 2 selection groups are given in Table 1.

Fertility EBV for cows in the experiment were extracted from the September 2009 routine genetic evaluation and used for calculation of genetic trends in the selection groups. A total of 5,001 cows from the selection experiment had fertility EBV, of which 2,806 were HPY and 2,195 were LCM cows. A total of 68 sires used in HPY and 57 sires used in LCM were present in the data. The distribution of selection experiment cows over selection groups and cow-generations are given in Table 2.

\section{Selection Response}

Genetic trends for the 2 selection groups were obtained by calculating mean EBV per cow-generation, up to cow-generation 6 . Cows in later cow-generations were excluded from the genetic trend calculations because of low numbers (Table 2). Permutation tests, where cows were assigned randomly to 2 groups, were used to test whether the mean EBV in the 2 selection groups were significantly different. For each trait, 10,000 permutations were performed, and the differences between mean EBV in the 2 randomly assigned groups were computed 
a)

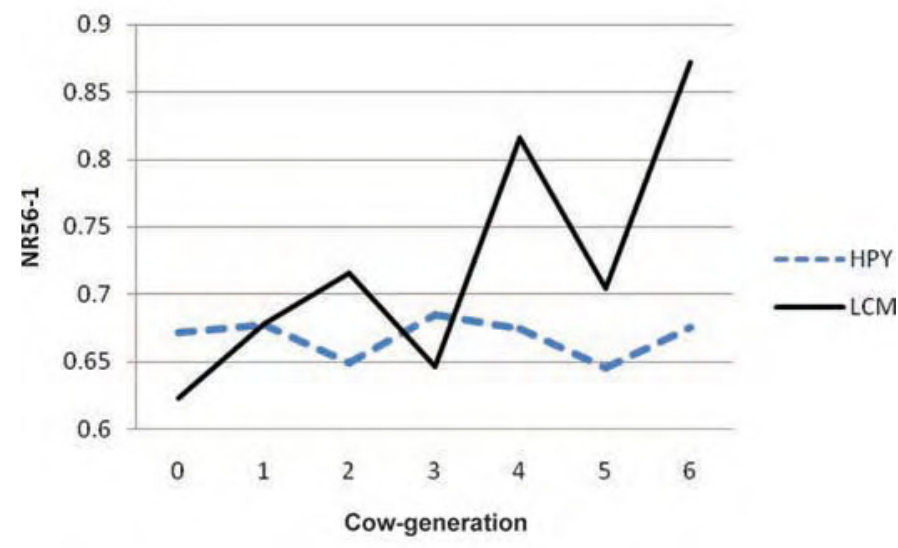

b)

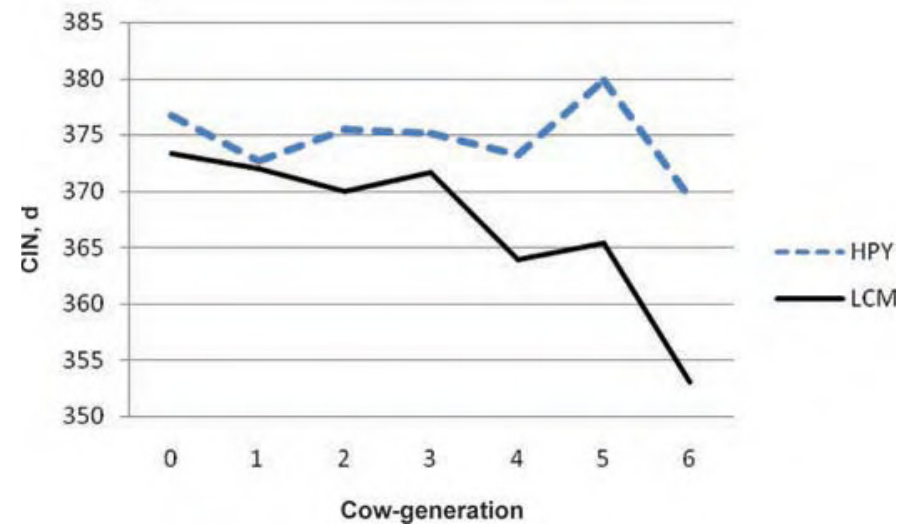

Figure 1. Phenotypic trends; mean nonreturn rate within $56 \mathrm{~d}$ in first-lactation cows (NR56-1) and mean calving interval (CIN) between first and second calving by cow-generation for groups of cows selected for high protein yield (HPY) and low clinical mastitis (LCM). Color version available in the online PDF.

per cow-generation. The observed differences in mean EBV between HPY and LCM in each generation were then compared with differences in mean EBV from the permutations. The proportion of sampled permutations where the difference was greater than the observed difference gave the significance level. For example, if the observed difference were contained within the middle $95 \%$ of permutation samples, the hypothesis of no difference between mean EBV in the 2 groups could not be rejected at $5 \%$ significant level. If the observed difference is outside the range from the permutation test, the difference is significantly different from zero with $P<0.0001$.

\section{RESULTS AND DISCUSSION}

Cows in the LCM group in general showed better phenotypic levels (Table 1) and fertility trends than
Table 2. Distribution of number of cows with fertility EBV over cowgenerations and the selection groups high protein yield (HPY) and low clinical mastitis (LCM)

\begin{tabular}{lrr}
\hline Cow-generation & HPY & LCM \\
\hline 0 & 470 & 299 \\
1 & 737 & 497 \\
2 & 520 & 435 \\
3 & 430 & 369 \\
4 & 329 & 314 \\
5 & 214 & 196 \\
6 & 88 & 77 \\
7 & 18 & 8 \\
Total number & 2,806 & 2,195 \\
\hline
\end{tabular}

HPY cows. The largest phenotypic differences were found for first-lactation NR56 and for CIN; the phenotypic trends for these 2 traits are given in Figure 1. Cows in the HPY group showed a flat phenotypic trend for NR56, whereas NR56 increased with cow-generation in LCM. The overall trend for CIN was relatively flat for HPY and decreasing for LCM.

Genetic trends for NR56 in heifers given as mean EBV by cow-generation and birth year are given in Figure 2. The overall genetic trend was relatively flat for HPY, whereas mean EBV increased with cowgeneration for LCM. After 6 cow-generations, the genetic difference between HPY and LCM cows was 2.5 percentage units NR56. To compare genetic trends in the selection groups to genetic trends in the Norwegian Red population, mean EBV were plotted per cow birth year. For the selection groups, the curves showing genetic trends by birth year were less smooth than those showing trends by cow-generation because cows born in the same year may belong to different cow-generations. Figure 2 shows that the mean EBV for both selection groups were below the mean EBV for Norwegian Reds, in which genetic improvement of NR56 in heifers has occurred over the last $25 \mathrm{yr}$. This explains why the genetic trend in HPY was flat despite an unfavorable genetic correlation between fertility and milk production. Sires used in the selection experiment were selected among progeny-tested Norwegian Red sires and were thus preselected for the Norwegian Red breeding objective, which has had a strong emphasis on fertility over the past $30 \mathrm{yr}$ (Geno Global, 2010). Sires used in the HPY group were therefore likely to be better on average for fertility than if they had been selected for increased milk production only. The generally good fertility level in Norwegian Reds should be kept in mind when interpreting these results, as should the on average moderate milk yield in Norwegian dairy herds.

Genetic trends for NR56 in first-lactation and secondand third-lactation cows are given in Figure 3. The 2 traits show similar genetic trends; the overall trends 
a)

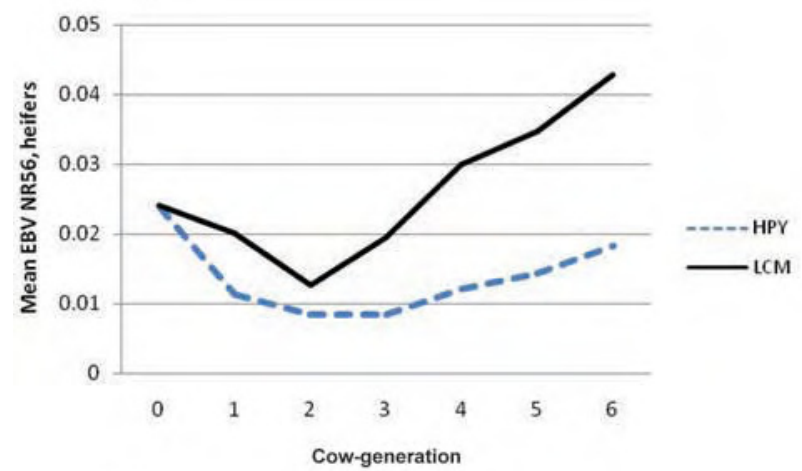

b)

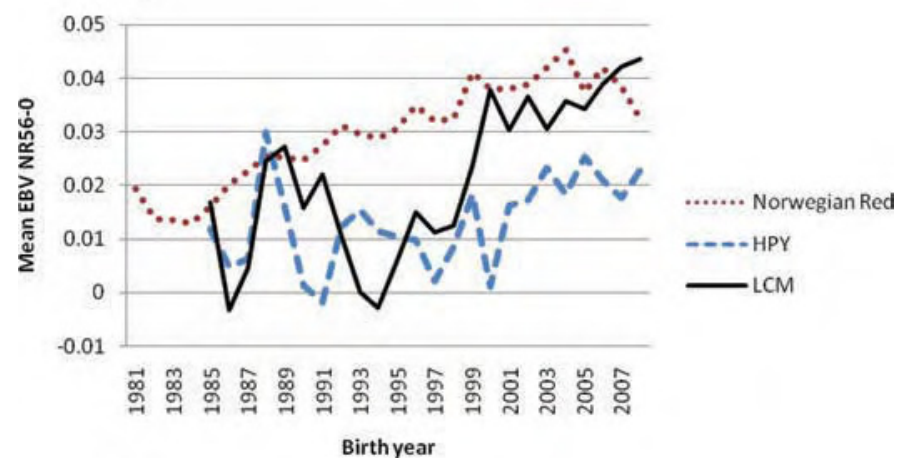

Figure 2. Genetic trends; mean EBV for nonreturn rate within 56 d in heifers (NR56-0) by cow-generation for groups selected for high protein yield (HPY) and low clinical mastitis (LCM) (a), and by cows birth year for HPY and LCM cows together with the Norwegian Red population (b). Color version available in the online PDF.

for NR56 in cows were decreasing for HPY and flat or slightly increasing for LCM, resulting in a genetic difference after 6 cow-generations of about 2 percentage units NR56. Heringstad et al. (2006b) estimated genetic correlations between NR56 and CM in first lactation close to zero. The genetic differences in NR56 in cows are therefore most likely to be correlated with selection for milk production.

Mean EBV for CIN per cow-generation are given in Figure 4 and indicate a genetic difference of about $4 \mathrm{~d}$ between HPY and LCM after 6 cow-generations. This is mainly a result of genetic improvement in the LCM group, in which a favorable deceasing trend for CIN was observed.

Figure 5 shows genetic trends for CFI in the 2 selection groups. Here the correlated response was less clear. For CFI in first-lactation cows, the genetic difference of 1 to $2 \mathrm{~d}$ found in generations 1 to 5 was reduced to zero in generation 6 . The genetic trends for CFI in secondand third-lactation cows were flat and partly overlapping in the 2 selection groups, and no indications of genetic differences between LCM and HPY were found for this trait.
Permutation tests were used to test whether the observed differences between mean EBV in the 2 selection groups were significantly different. Results of the permutation test for NR56 in heifers are given in Figure 6, showing the distributions of the difference in mean EBV per cow-generation, based on 10,000 permutations with cows assigned randomly to 2 groups. All distributions were sharp and symmetric, but with higher SD for the 2 last cow-generations as a result of fewer cows in the later generations (Table 2). Similar distributions were found for the other traits (figures not shown). Table 3 gives the observed difference between mean EBV in HPY and LCM per cow-generation for the 6 fertility traits together with the maximum differences (absolute value) in mean EBV from the permutation tests. Except for CFI in second- and third-lactation cows and CFI in first-lactation cow-generation 6 , all observed differences between HPY and LCM, from cow-generation 1 on-

a)

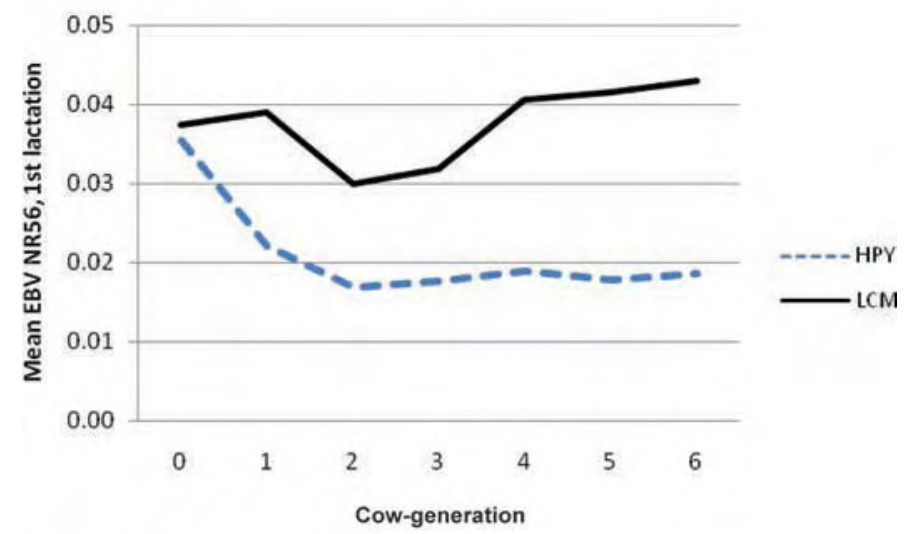

b)

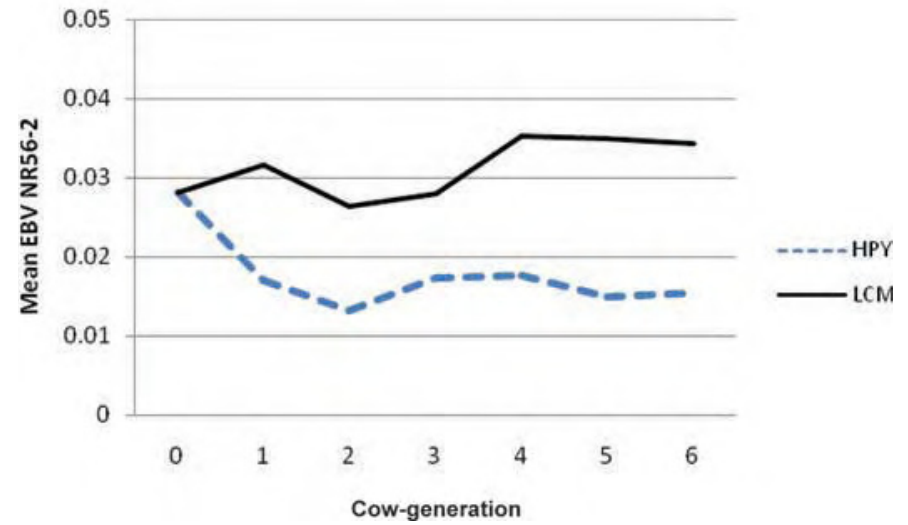

Figure 3. Genetic trends; mean EBV for nonreturn rate within $56 \mathrm{~d}$ in first-lactation cows (NR56-1) and second- and third-lactation cows (NR56-2) by cow-generation for groups selected for high protein yield (HPY) and low clinical mastitis (LCM). Color version available in the online PDF. 


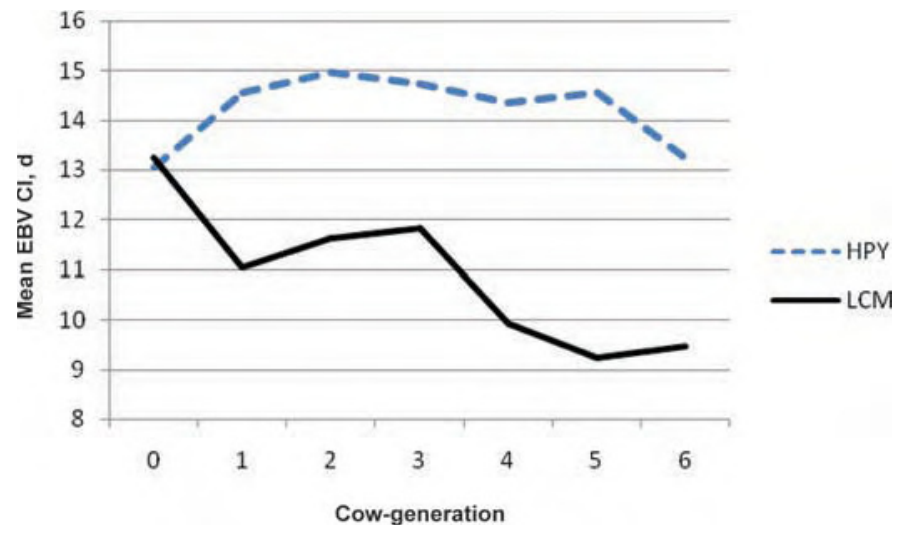

Figure 4. Genetic trends; mean EBV for calving interval (CIN) by cow-generation for groups selected for high protein yield (HPY) and low clinical mastitis (LCM). Color version available in the online PDF.

wards, were significantly different (Table 3 ). Observed differences far outside the range of the permutation test imply that the observed differences were unlikely to have occurred by chance $(P<0.0001)$.

Correlated selection responses for female fertility, in opposite directions, were found in HPY and LCM. Because of unfavorable genetic correlations between milk production and fertility (e.g., Roxström et al., 2001; Andersen-Ranberg et al., 2005), a genetic deterioration of fertility traits has occurred in the HPY group. On the other hand, positive genetic correlations between mastitis and fertility (e.g., Andersen-Ranberg and Heringstad, 2006) have resulted in genetic improvement of fertility traits in the LCM group. Our findings of correlated selection responses for female fertility after selection for increased protein yield were generally in agreement with previous studies. In a review of direct and correlated responses to selection for milk yield from selection experiments in the United States, Kelm and a)

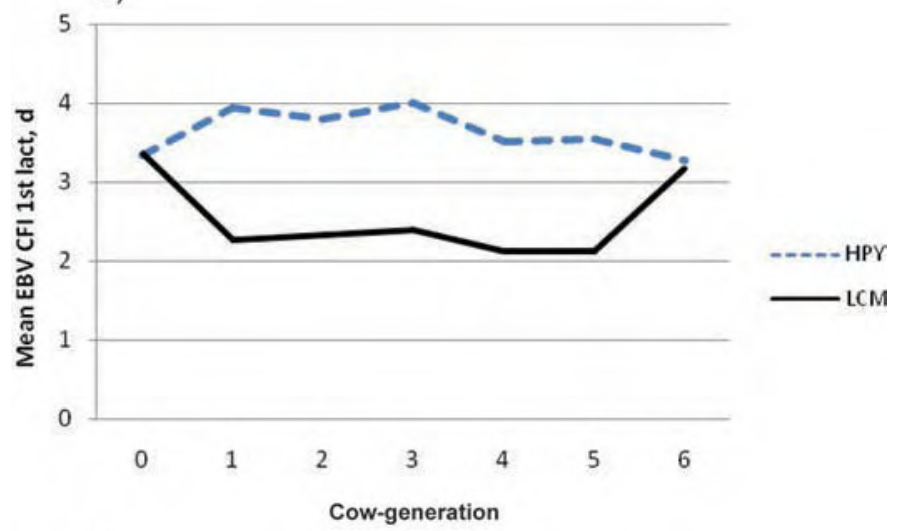

b)

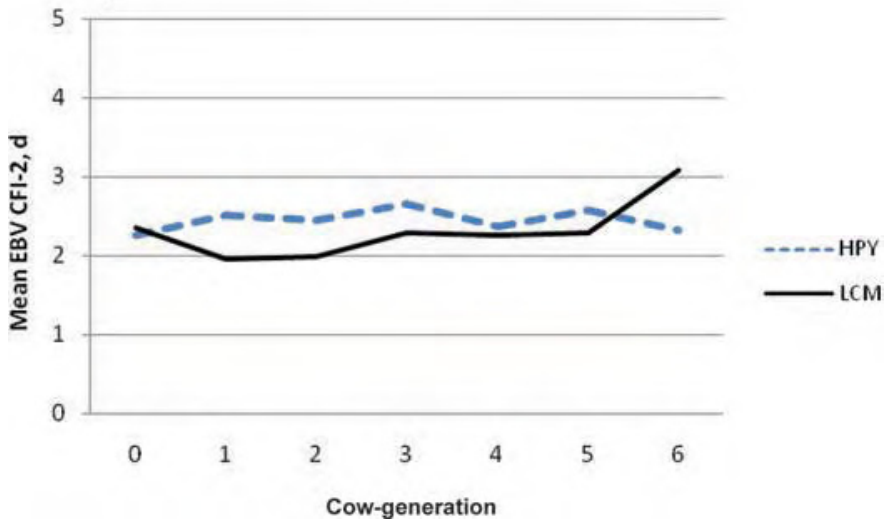

Figure 5. Genetic trends; mean EBV for interval from calving to first insemination (CFI) in first (CFI-1) and second and third (CFI-2) lactation by cow-generation for groups selected for high protein yield (HPY) and low clinical mastitis (LCM). Color version available in the online PDF.

Freeman (2000) concluded that selection for milk yield did not affect fertility of virgin heifers, but usually delayed estrus of lactating cows. They found that cows from high-milk-yield lines had a longer interval from

Table 3. Observed difference in mean EBV (Obs) per cow-generation (Gen) between high protein yield (HPY) and low clinical mastitis (LCM) cows and maximum difference (absolute value) from permutation test (Max) for nonreturn rate within 56 d for heifers (NR56-0), first-lactation cows (NR56-1), and second- and third-lactation cows (NR56-2), calving interval (CIN), and interval from calving to first insemination for firstlactation cows (CFI-1) and second- and third-lactation cows (CFI-2)

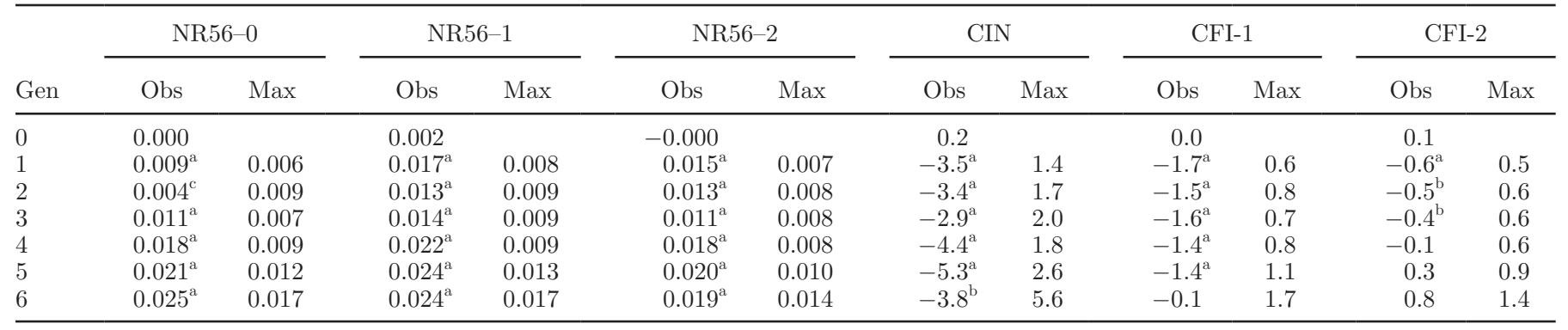

${ }^{a}$ Observed value outside the range of the permutation test $(P<0.0001)$.

${ }^{\mathrm{b}}$ Observed value outside the middle $99 \%$ of samples from permutation test $(P<0.01)$.

'Observed value outside the middle $95 \%$ of samples from permutation test $(P<0.05)$. 


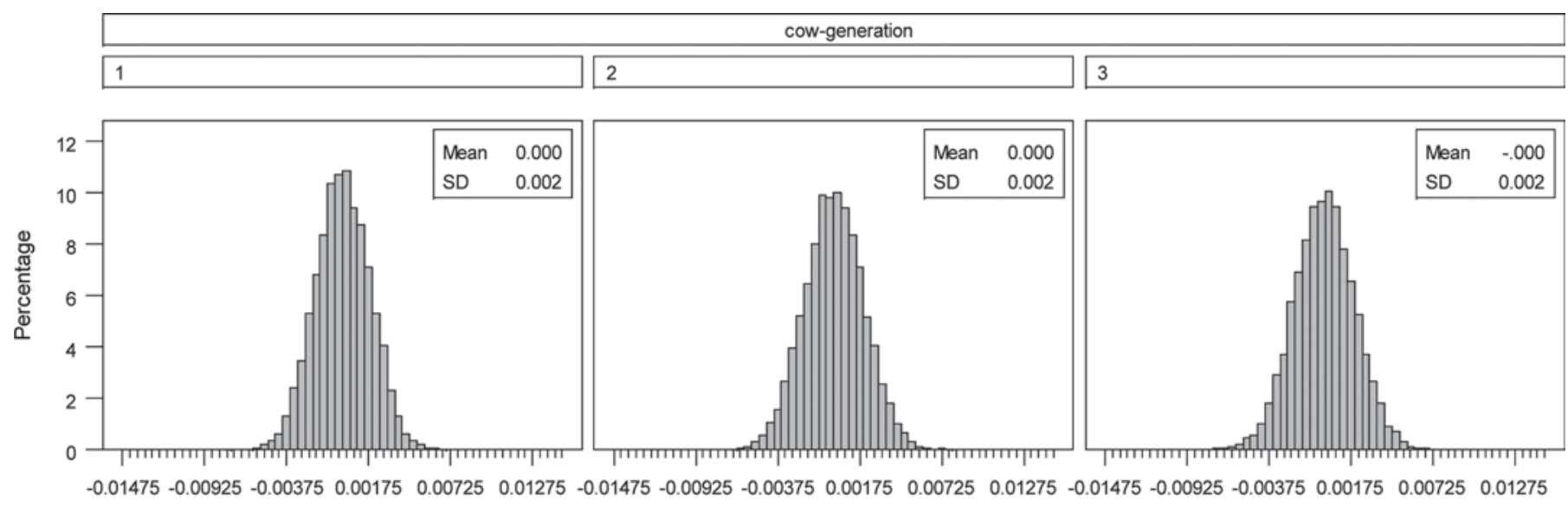

Difference in mean EBV

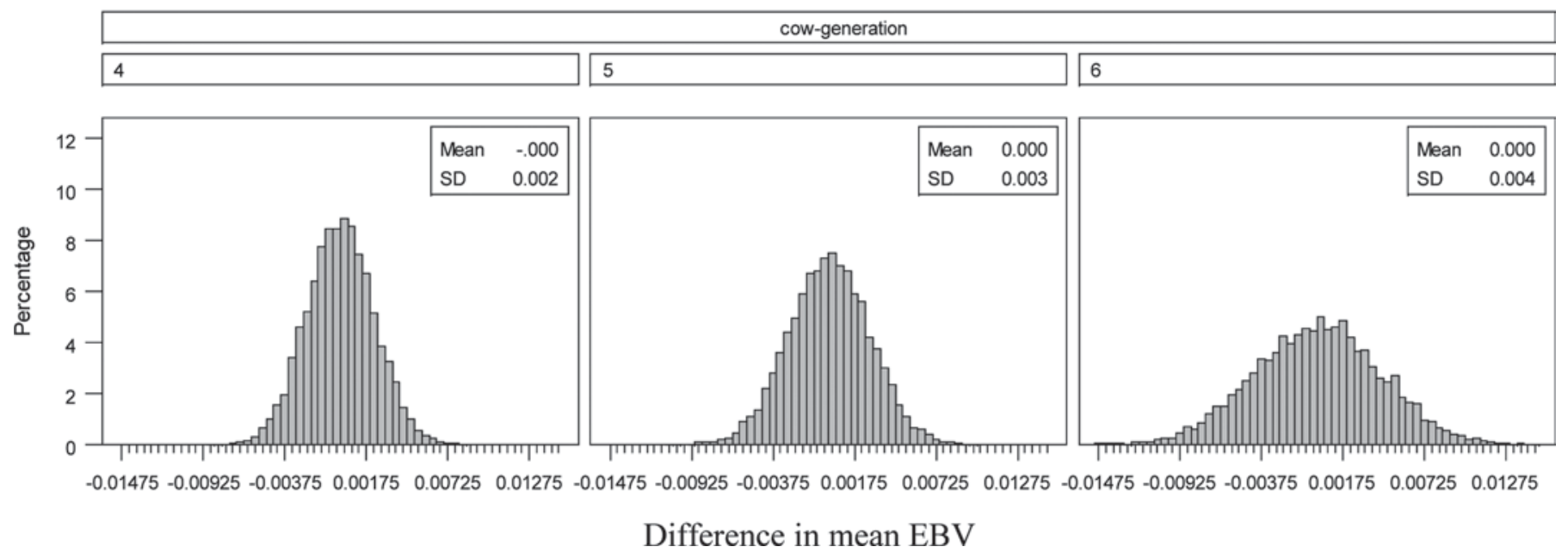

Figure 6. The distribution of the difference in mean cow EBV for nonreturn within $56 \mathrm{~d}$ after first insemination in heifers per cow-generation, based on 10,000 permutations with cows assigned randomly to 2 groups.

calving to first estrus, longer interval from calving to first breeding, more days open, and a longer calving interval than cows in average-milk-yield lines. From a long-term selection experiment with Jerseys, Bonczek et al. (1992) found no significant differences between the high-milk-yield group and the control group in heifer fertility. In primiparous cows, they found significantly longer intervals from calving to first breeding, and from calving to conception in the high-milk-yield group.

This is, as far as we know, the only selection experiment involving direct selection against clinical mastitis. The present study is therefore the first to report genetic changes in female fertility as a correlated response after selection against mastitis.

Previous studies (Heringstad et al., 2007, 2008) have shown that selection for high protein yield in HPY resulted in unfavorable correlated selection responses in resistance to clinical mastitis as well as other diseases and lactation mean SCS, whereas the side effects of selection against mastitis in LCM included increased resistance to other diseases and reduced lactation mean SCS. These results together with the present study demonstrate that whereas selection only or mainly for milk production results in genetic deterioration of health and fertility, selection against mastitis can be viewed as indirect selection for more robust cows, with genetic improvement of health and fertility as correlated responses.

\section{ACKNOWLEDGMENTS}

Geno Breeding and A.I. Association (Ås, Norway), and the herds at the Norwegian University of Life Sciences, Ana fengsel, and the agricultural schools; Buskerud (from 2008, Johan Kopland), Gjermundnes, Jønsberg, Kalnes, Mære, Valle, and Øksnevad are acknowledged 
for running the selection experiment. Access to the data was given by the Norwegian Dairy Herd Recording System and the Norwegian Cattle Health Service. We thank Daniel Gianola (University of Wisconsin, Madison) for his suggestion of using permutation tests to test whether the selection groups were significantly different.

\section{REFERENCES}

Andersen-Ranberg, I. M., and B. Heringstad. 2006. Genetic associations between female fertility, mastitis and protein yield in Norwegian Red. Proceedings of 8th WCGALP, Belo Horizonte, Brazil. Communication No. 01-20. 8WCGALP, Belo Horizonte, Brazil.

Andersen-Ranberg, I. M., G. Klemetsdal, B. Heringstad, and T. Steine. 2005. Heritabilities, genetic correlations, and genetic change for female fertility and protein yield in Norwegian dairy cattle. J. Dairy Sci. 88:348-355.

Bonczek, R. R., D. O. Richardson, E. D. Moore, R. H. Miller, J. R. Owen, H. H. Dowlen, and B. R. Bell. 1992. Correlated responses in reproduction accompanying selection for milk yield in Jerseys. J. Dairy Sci. 75:1154-1160.

Geno Global. 2010. Norwegian Red characteristics. Breeding objective. http://www.genoglobal.no/Home/Norwegian-Red-Characteristics/Norwegian-Red/ Accessed June 16, 2010.

Heringstad, B., I. M. Andersen-Ranberg, Y. M. Chang, and D. Gianola. 2006b. Short communication: Genetic analysis of nonreturn rate and mastitis in first-lactation Norwegian Red cows. J. Dairy Sci. 89:4420-4423.

Heringstad, B., Y. M. Chang, I. M. Andersen-Ranberg, and D. Gianola. 2006a. Genetic analysis of number of mastitis cases and number of services to conception using a censored threshold model. J. Dairy Sci. 89:4042-4048.

Heringstad, B., G. Klemetsdal, and T. Steine. 2007. Selection responses for disease resistance in two selection experiments with Norwegian Red cows. J. Dairy Sci. 90:2419-2426.

Heringstad, B., E. Sehested, and T. Steine. 2008. Short communication: Correlated selection responses in somatic cell count from selection against clinical mastitis. J. Dairy Sci. 91:4437-4439.

Interbull. 2010. Description of GSE as applied in member countries. http://www-interbull.slu.se/national_ges_info2/framesida-ges. htm Accessed Jan. 18, 2010.

Kadarmideen, H. N., R. Thompson, and G. Simm. 2000. Linear and threshold model genetic parameters for disease, fertility and milk production in dairy cattle. Anim. Sci. 71:411-419.

Kelm, S. C., and A. E. Freeman. 2000. Direct and correlated responses to selection for milk yield: Results and conclusions of regional project NC-2, "improvement of dairy cattle through breeding, with emphasis on selection". J. Dairy Sci. 83:2721-2732.

Larsgard, A. G. 2008. A new fertility index in Norwegian Red. Page 77 in Proc. 59th Annual Mtg. of the EAAP, Vilnius, Lithuania. Wageningen Academic Publishers, Wageningen, the Netherlands.

Roxström, A., E. Strandberg, B. Berglund, and U. Emanuelson. 2001. Genetic and environmental correlations among female fertility traits and milk production in different parities of Swedish Red and White dairy cattle. Acta Agric. Scand. 51:7-14 